\title{
Screening of some seaweeds species from South Sinai, Red Sea as potential bioinsecticides against mosquito larvae; Culex pipiens
}

\author{
Shereen M. Elbanna ${ }^{1}$ and Muhammad M. Hegazi ${ }^{2}$ \\ 1-Zoology Department, Faculty of Science, Suez Canal University, Ismailia, Egypt \\ 2- Department of Marine Biology, Faculty of Science, Suez Canal University, Ismailia, Egypt \\ Email:sh_elbana@hotmail.com
}

\section{ABSTRACT}

On searching for bioinsecticides virulent to mosquito larvae; Culex pipiens, nine seaweeds species were screened. In this study, different dried seaweeds were applied into the mosquito larvae rearing jars. The effect of these seaweeds on the survival, larval development and growth rate of the mosquito Culex pipiens larvae was measured. The percentage of dead larvae fed with seaweeds species after 10 and 15 days were $50 \%, 90 \%$ respectively. Delayed pupation and body size reduction of the mosquitoes larvae fed with seaweeds were observed. The study showed that Caulerpa prolifera, Caulerpa serrulata, Jania rubens, Nitophyllum punctatum, Cystoseira myrica and Padina pavonica have potential to be used as larvicidal agents acting mainly to increase life cycle intervals and pupation delay.

Keywords: Seaweeds, chemical defense, bioinsecticides, Culex pipiens larvae

\section{INTRODUCTION}

Mosquitoes serve as a vector of several diseases, causing serious health problems to human; they transmit diseases such as yellow fever, human lymphatic filariasis and malaria (Abdel-Hameed, et al., 1994). Mosquito problem has become acute in recent years; so many programmes have been launched to control these vectors. Synthetic insecticides are well recognized for their speedy action but a major drawback in their application is that they are non-selective and could be harmful to other beneficial organisms, animals and human beings (Abdel-Hameed, 1991). Besides their adverse environmental effects, pests and mosquito disease vector have become physiologically resistant to many of the synthetic pesticides (Rao et al., 1995 and 1999). All these restrictions on the usage of synthetic pesticides have stimulated investigations for an environmentally safe, degradable and target specific insecticides against mosquitoes. Ultimately phytochemicals with anti-larval properties, derived from various botanical sources. Quite a lot of work has been carried out in higher plants on their biologically active material with anti-larval properties (Campbell \& Sullivan, 1933; Hartzell et al., 1958 and Saxena \& Sumithra, 1985). It was recently reported that the neuro- and hepato-toxins of some cyanobacterial strains are toxic to mosquito larvae (Kiviranta, et al., 1993 and Kiviranta \& Abdel-Hameed, 1994). Few attentions were focused on the larvicidal properties of the fresh and marine water algae (Hamlyn-Harris, 1928; Griffin, 1956; Dhillon \& Mulla, 1981; Semakov \& Sirenko, 1985 and Pucazhendi, et al., 1995). Although most algae are nutritious food for mosquito larvae, some species kill the larvae when ingested in large quantities (Marten, 1987 \& 2007), while blue-green algae toxins may offer possibilities for delivery as larvicides. Certain species of green algae kill larvae primarily because they 
are indigestible. More research on the possible toxic effect of algae extraction on mosquito is needed. The present study was designed to screen different types of seaweeds species on Culex pipiens (Diptera; Culicidae) larvae for both larvacidal and/or developmental effects.

\section{MATERIAL AND METHODS}

South Sinai area was studied during a number of reconnaissance field trips, extensive collections were done from different depths and habitats. The seaweeds collected by different methods in order to secure complete alga.

Field containers: Plastic containers were used, but for intertidal collection, buckets and bags for various sizes were used, and for the subtidal collection by SCUBA diving perforated plastic bags were used.

Species Identification: All selected species (Caulerpa prolifera, Caulerpa serrulata, Enteromorpha intestinalis, Ulva lactuca, Jania rubens, Sarconema filiforme, Nitophyllum punctatum, Cystoseira myrica and Padina pavonica) had been identified and compared with materials in the Marine Botany Laboratory, Marine Science Department, Suez Canal University (Plate 1). Seaweeds were collected and dried by air flow at room temperature until used.

Preparing the algae for bioassay: The dried seaweeds were crushed into very tiny small pieces before be used in the bioassay.

Bioassay: Culex pipiens larvae were supplied from Ain shams center for epidemic disease control. Larvae for bioassays were reared under uncrowded conditions from eggs removed from a main colony. Eggs were removed daily so that their age never varied by more than 24 hours. Seven days after the date of deposition of the eggs ( 3 to 4 days after eggs hatched), second-instar larvae were selected for use in a bioassay. Trays were filled with water at $10 \mathrm{~cm}$ depth, with dist. Water and left overnight so the water took the room temperature. During The second day, eggs, larvae, pupa were added to the tray, fish food were also added for feeding larvae. The mosquito larvae originally collected from wild populations at Ain shams area, Cairo. Eggs hatched in autoclaved tap water to which no food for mosquito larvae was added. Larvae were pipetted into test jars within $24 \mathrm{~h}$ of hatching. Only ten larvae were used in each replicate to ensure that larval grazing did not reduce algal densities. The test was repeated and considered conclusive only if the same result occurred the second time. If the second result was not the same, the test was repeated until a pattern emerged as in Fig 1.

Each replicate for a bioassay consisted of $50 \mathrm{ml}$ of laboratory water (aged tap water, in a clear, (Strickman, 1985) glass jar (50-ml capacity). The desired amount of algae was added to each replicate at an appropriate concentration. The appropriate amount of food (Tetramin Baby Fish Food "E," Tetra Werke Mille, West Germany) was placed in each replicate and the jars covered with paraffin film to prevent evaporation. Bioassays were maintained in an environmental chamber at $23^{\circ} \mathrm{C}$ with a 14-hour daily photophase. For survival, Larvae were observed daily stage of development, and behavioral signs of intoxication. Food was added at each observation in proportion to number of survivors and their stages of development. Bioassays lasted 20 days, during which time most larvae in laboratory water completed development to the fourth instar.

Statistical Analysis: System was used to perform statistical analysis of survival and development. Survival was analyzed by calculating means of total survivors on each day of a bioassay for each concentration. Differences among daily means for each 
concentration were determined at the 95\% level using SPSS. Development was analyzed by examining the number of third-instar larvae on each day of the bioassay. Previous studies (Strickman, 1985) had indicated that the third instar is representative of developmental effects throughout the juvenile life. Adjustments of number of fourth-instar larvae for total survival within the replicate (the number of fourth instars multiplied by 10 , then the product divided by the total number of survivors in that replicate) allowed comparison of development independent of survival. This adjustment was possible only in concentrations where at least 1 larva remained alive in each replicate. Results of the entire concentration treatment were eliminated from analysis when any of its replicates contained no living larvae. Means of adjusted number of fourth instars were analyzed similarly to means of number of survivors.
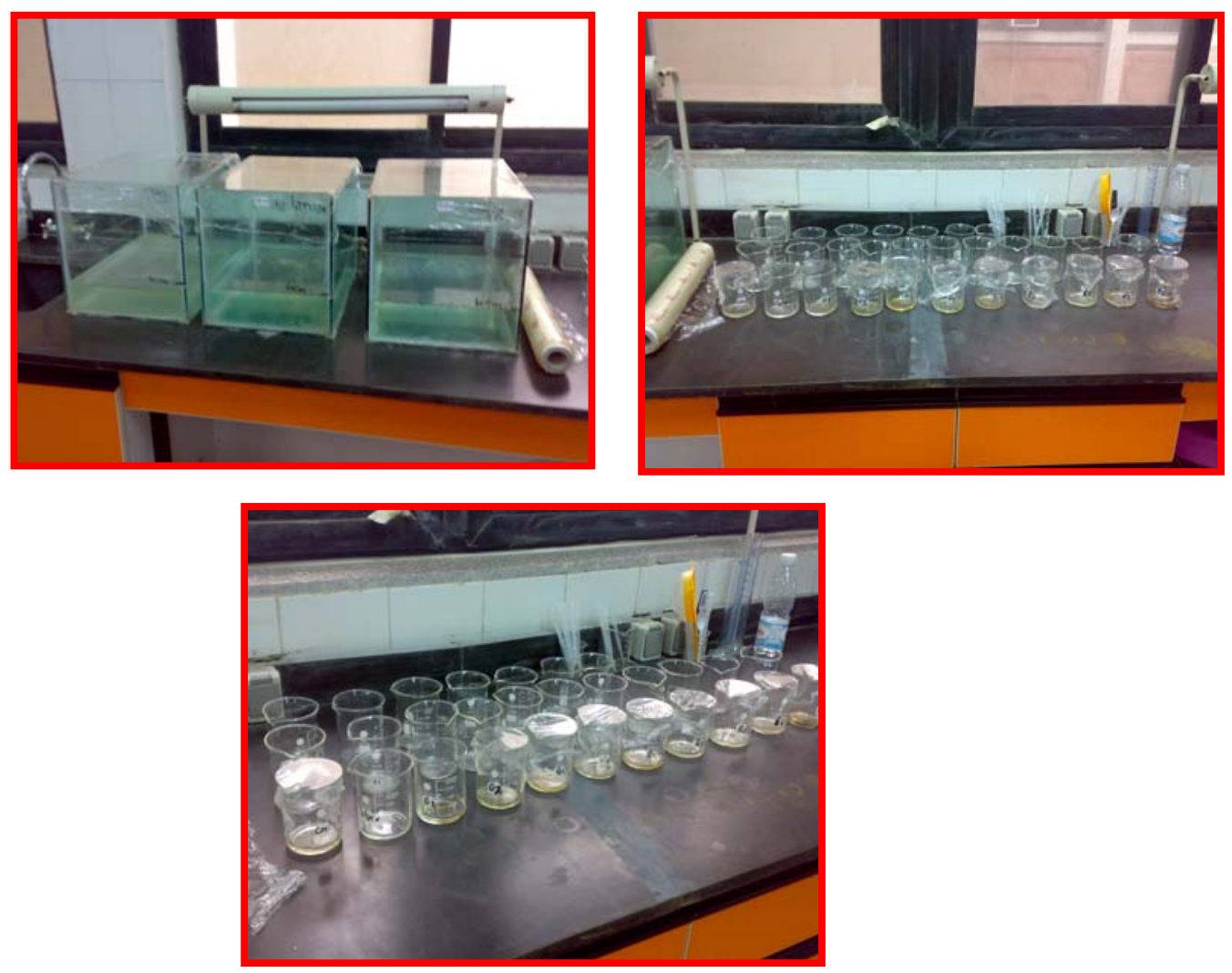

Fig. 1: Methods of rearing and bioassay of the Seaweeds as a bioinsecticides for mosquito larvae

\section{RESULTS AND DISCUSSION}

Seaweeds are a fascinating and diverse group of organisms living in the earth's Seas and oceans. Seaweeds play very important ecological roles in many marine communities. They are a food source for marine animals such as sea urchins and fishes, and are the nutritional base of some food webs. They also provide shelter and a home for numerous fishes, invertebrates, and mammals. The different groups of algae are a significant part of the diet for many kinds of mosquito larvae that feed on microorganisms, small aquatic animals such as rotifers, and other small particulate food in their aquatic environment (Merritt, et al., 1992). The larvae may filter algae from the water column, scrape them from the surface of containers or aquatic plants, or scoop them from the bottom of aquatic habitats where mosquitoes breed. Most kinds of phytoplankton are good food for mosquito larvae (Coggeshall, 1926; Marten, 1984 and Merritt, et al., 1992). Marine plants are continuously being challenged by 
microorganisms and by grazers. It appears that this intense grazing has provided strong selection for seaweeds that synthesize unique secondary metabolites that significantly reduce the consumption of plants exposed to attack by a diverse group of reef herbivores (Hay, et al., 1987a \& 1987b and Hay, 1988). Seaweeds possess morphological, structural, mineral $\left(\mathrm{CaCO}_{3}\right)$, and chemical traits that deter reef herbivores. Seaweeds combine several of these defensive traits and, in some instances, these act additively or synergistically to reduce losses to herbivores. In our study, a broad spectrum of algae species were screened for their effect on Culex pipiens mosquito larvae.

In the control treatment, where the $2^{\text {nd }}$ instar larvae fed with dried fish food, the $2^{\text {nd }}$ instars transformed to adults after 7 days while the starved larvae died after 7 days, Table 1. All larvae develop to third instars at day 4 and to fourth instars at day 5 and they develop normally to adult at day 12 no dead larvae were recorded. From the experiment at which dried marine algae were fed to the $2^{\text {nd }}$ instar larvae, the larvae neither die nor develop normally, (Table 1). Groups of larvae that received dried algae survived but they didn't go through the normal development in comparison with the control group, significantly different from the control $\rho>0.0005$. This study shows that the brown algae Padina pavonica is the most effective species affect significantly the larvae growth rate rather than Cystoseira myrica as all mosquito larvae died at day 10 with $\rho>0.0001$ while in case of larvae fed with Cystoseira died at day 17 . None of larvae treated with Padina pavonica reached fourth larval instars significantly different from the control $\rho>0.0005$ while larvae treated with Cystoseira reached fourth larval instars (Fig. 2.b). Larvae in both treatments were significantly affected and didn't reach the pupa stage, (Fig. 2.b) due to the levels of protective polyphenolic compounds of brown algae as important chemical defense (Duffy \& Hay, 1990 and Steinberg et al., 1991) significantly reducing palatability in response to direct mosquito attacks. These results coincide with those reported by Pucazhendi, et al. (1995) who noticed that Padina pavonica and Zonaria sp both were found to be most effective seaweeds. For red algae, Sarconema filiforme has the least effect on the mosquito larvae as most of the larvae reached the pupa stage and none dead larvae was recorded. Larvae treated with dried Nitophyllum punctatum or Jania rubens died and none of the larvae develop normally, significantly different from the control treatment $\rho>0.0005$, (Fig 2.c) due to the precipitate of calcium carbonate which make Jania harder to be eaten and more difficult against predators. The larvicidal effect of Jania may be due to bioactive phytoconstituents such as carotenoids (Hegazi, et al., 1998 and Ahmed, et al., 2011). In the present study, the brown and red algae exhibited somewhat higher activity on the larvae growth rate compared to the other seaweeds. Red algae are being considered the most important source of many biologically active metabolites in comparison to other algal classes (El-Gamal, 2010). The present results suggested that brown algae revealed the highest effect on larvae growth rate, this may be due to brown algae contain high phenolic contents, these results are in agreement with those of Zubia, et al. (2008). Another explanation of Zubia, et al. (2008) reported that brown algae produce a specific type of tannin called phlorotannins. This larvicidal effect of brown algae may be due to phenolic, terpenoids or unsaturated fatty acids (Schnitzler, et al., 2001). It was reported in the literature that the cytotoxic activity of some red and brown algal species could be attributed to the presence of a mixture of organic acids (Kamenarska et al., 2002 and 2007). For green algae, species of algae with leaf shape Ulva lactuca and Enteromorpha intestinalis have none of the same effect as other algae, larvae treated with these leaf shape algae develop normally, (Fig, 2.a) due to that both Ulva and 
Enteromorpha had a high nitrogen content and a moderate organic content, so, it is the most preferred species by mosquitoes larvae. Caulerpa prolifera and Caulerpa serrulata are the most effective of the green algae as none of the larvae treated with these green algae, reached the fourth instars and larvae died before reached pupa stage, this effect was significantly different from control treatment $\rho>0.001$, (Fig 2.a) may be due to their containing many types of distasteful, caulerpenyne, terpenoids and nitrogenous compounds. Caulerpenyne is the major secondary metabolite involved in the chemical defense of genus Caulerpa.

Table 1: Showing the numbers of larvae for both dead and fourth instar in the selected species during the experimental period: (G1) Caulerpa prolifera (G2) Ulva lactuca (G3) Caulerpa serrulata (G4) Enteromorpha intestinalis (B1) Padina pavonica (B2) Cystoseira myrica (R1) Sarconema filiforme (R2) Nitophyllum punctatum and (R3) Jania rubens.

\begin{tabular}{|c|c|c|c|c|c|c|c|c|c|c|c|}
\hline Day1 & G1 & G2 & G3 & G4 & B1 & B2 & R1 & $\mathbf{R 2}$ & $\mathbf{R 3}$ & Control & Starvation \\
\hline No. dead larvae & 0 & 0 & 0 & 0 & 0 & 0 & 0 & 0 & 0 & 0 & 0 \\
\hline No of fourth & 0 & 0 & 0 & 0 & 0 & 0 & 0 & 0 & 0 & 0 & 0 \\
\hline \multicolumn{12}{|l|}{ Day2 } \\
\hline No. dead larvae & 0 & 0 & 0 & 0 & 0 & 0 & 0 & 0 & 0 & 0 & 0 \\
\hline No of fourth & 0 & 0 & 0 & 0 & 0 & 0 & 0 & 0 & 0 & 0 & 0 \\
\hline \multicolumn{12}{|l|}{ Day3 } \\
\hline No. dead larvae & 0 & 0 & 0 & 0 & 0 & 0 & 0 & 0 & 0 & 0 & 0 \\
\hline No of fourth & 0 & 0 & 0 & 0 & 0 & 0 & 0 & 0 & 0 & 0 & 0 \\
\hline \multicolumn{12}{|l|}{ Day4 } \\
\hline No. dead larvae & 0 & 0 & 0 & 0 & 1 & 0 & 1 & 0 & 0 & 0 & 0 \\
\hline No of fourth & 0 & 0 & 0 & 0 & 0 & 0 & 0 & 0 & 0 & 10 & 0 \\
\hline \multicolumn{12}{|l|}{ Day5 } \\
\hline No. dead larvae & 0 & 0 & 0 & 0 & 1 & 0 & 1 & 0 & 0 & 0 & 0 \\
\hline No of fourth & 0 & 7 & 0 & 3 & 2 & 0 & 0 & 0 & 0 & 10 & 0 \\
\hline \multicolumn{12}{|l|}{ Day6 } \\
\hline No. dead larvae & 0 & 0 & 0 & 1 & 1 & 0 & 1 & 0 & 0 & 0 & 0 \\
\hline No of fourth & 0 & 7 & 0 & 3 & 0 & 0 & 4 & 0 & 0 & 10 & 0 \\
\hline \multicolumn{12}{|l|}{ Day7 } \\
\hline No. dead larvae & 0 & 0 & 0 & 1 & 1 & 0 & 1 & 0 & 0 & 0 & 0 \\
\hline No of fourth & 0 & 8 & 0 & 6 & 0 & 0 & 4 & 0 & 0 & 10 & 0 \\
\hline \multicolumn{12}{|l|}{ Day8 } \\
\hline No. dead larvae & 0 & 0 & 0 & 1 & 1 & 1 & 2 & 0 & 1 & 0 & 3 \\
\hline No of fourth & 0 & 9 & 0 & 6 & 0 & 0 & 4 & 0 & 0 & 10 & 0 \\
\hline \multicolumn{12}{|l|}{ Day9 } \\
\hline No. dead larvae & 1 & 0 & 2 & 1 & 3 & 3 & 2 & 2 & 1 & 0 & 9 \\
\hline No of fourth & 0 & 9 & 0 & 6 & 0 & 0 & 4 & 0 & 0 & 10 & 0 \\
\hline \multicolumn{12}{|l|}{ Day10 } \\
\hline No. dead larvae & 1 & 0 & 2 & 1 & 10 & 5 & 2 & 2 & 1 & 0 & 9 \\
\hline No of fourth & 0 & 9 & 0 & 7 & 0 & 0 & 6 & 0 & 0 & 10 & 0 \\
\hline \multicolumn{12}{|l|}{ Day11 } \\
\hline No. dead larvae & 3 & 0 & 3 & 1 & 10 & 5 & 2 & 5 & 4 & 0 & 10 \\
\hline No of fourth & 0 & 10 & 0 & 7 & 0 & 0 & 8 & 0 & 0 & 10 & 0 \\
\hline \multicolumn{12}{|l|}{ Day12 } \\
\hline No. dead larvae & 7 & 0 & 5 & 2 & 10 & 6 & 2 & 5 & 5 & 0 & 10 \\
\hline No of fourth & 0 & 10 & 0 & 7 & 0 & 0 & 8 & 0 & 0 & 10 & 0 \\
\hline \multicolumn{12}{|l|}{ Day13 } \\
\hline No. dead larvae & 9 & 0 & 8 & 2 & 10 & 7 & 4 & 7 & 7 & 0 & 10 \\
\hline No of fourth & 0 & 10 & 0 & 7 & 0 & 0 & 6 & 0 & 0 & 10 & 0 \\
\hline \multicolumn{12}{|l|}{ Day14 } \\
\hline No. dead larvae & 9 & 6 & 9 & 5 & 10 & 9 & 5 & 9 & 9 & 0 & 10 \\
\hline No of fourth & 0 & 4 & 0 & 5 & 0 & 0 & 5 & 0 & 0 & 10 & 0 \\
\hline \multicolumn{12}{|l|}{ Day15 } \\
\hline No. dead larvae & 10 & 6 & 9 & 7 & 10 & 9 & 7 & 9 & 9 & 0 & 10 \\
\hline No of fourth & 0 & 4 & 0 & 3 & 0 & 1 & 2 & 0 & 0 & 10 & 0 \\
\hline \multicolumn{12}{|l|}{ Day16 } \\
\hline No. dead larvae & 10 & 6 & 9 & 7 & 10 & 9 & 7 & 9 & 9 & 0 & 10 \\
\hline No of fourth & 0 & 4 & 0 & 3 & 0 & 1 & 2 & 0 & 0 & 10 & 0 \\
\hline \multicolumn{12}{|l|}{ Day17 } \\
\hline No. dead larvae & 10 & 7 & 10 & 7 & 10 & 9 & 8 & 10 & 10 & 0 & 10 \\
\hline No of fourth & 0 & 3 & 0 & 3 & 0 & 1 & 1 & 0 & 0 & 10 & 0 \\
\hline
\end{tabular}


Also caulerpenyne has demonstrated a variety of toxic effects in several organisms at different stages of their growth. The high degree of biological activity of caulerpenyne supports the hypothesis that this compound serves as a defense mechanism against herbivores, these coincide with the previous research of Cetin, et al. (2010) indicates that caulerpenyne represent an ecological risk for microorganisms and multicellular animals that live close to genus Caulerpa and contains components with larvicidal properties against mosquitoes.
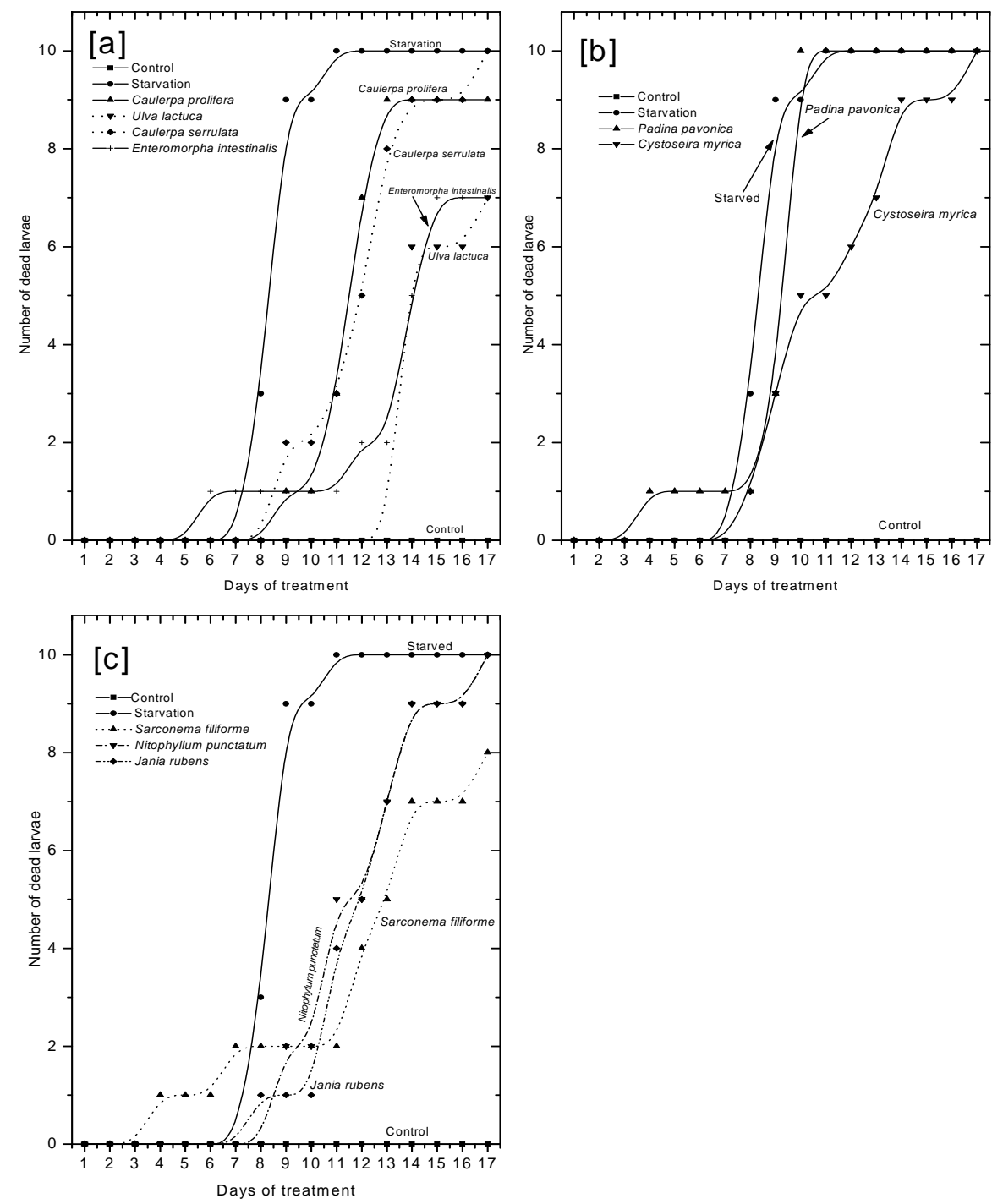

Fig. 2: Showing the number of dead larvae during the days of treatment with [a] green, [b] brown and [c] red seaweeds.

\section{REFERENCES}

Abdel-Hameed, A. (1991). Studies on certain locally isolated microbial control agents against certain insects or pests prevailing in Egypt. Ph.D. Thesis, Cairo University, Egypt.

Abdel-Hameed, A., J. Kiviranta, K. Sivonec, S. Nienela, and G. Carlberg (1994). Algae in mosquito breeding sites and the effectiveness of the mosquito 
larvicide Bacillus thuringiensis H14. World journal of Microbiology and Biotechnology, 8: 151-159.

Ahmed, H. H., M. M. Hegazi, H. I. Abd-Alla, E. F. Eskander and M. S. Ellithey (2011). Antitumour and Antioxidant Activity of some Red Sea Seaweeds in Ehrlich Ascites Carcinoma in vivo. Z. Naturforsch., 66c: 367-376.

Campbell, F. L., W. N. Sullivan and C. R. Smith (1993). The relative toxicity of nicotine, anabasine, methyl anabasine and lupinine for culicine mosquito larvae. J. Econ. Enomol., 26: 500-509.

Cetin H.; G. Mehmet, and O. Emre (2010). Larvicidal Activity of the Extract of Seaweed, Caulerpa scalpelliformis, Against Culex pipiens. Journal of the American Mosquito Control Association 26(4): 433-435.

Coggeshall L. (1926). Relationship of plankton to anopheline larvae. Am. J. Hygiene., 6: 556-596.

Dhillon M. S. \& M. S. Mulla (1981). Biological activity of the green algae Chlorella ellipsoidea against the immature mosquitoes. Mosq News 41: 368-372.

Duffy, J. M. and Hay, M. E. (1990). Seaweed adaptation to herbivory. Bioscience, 40: 368-375.

El Gamal, A. A. (2010). Biological importance of marine algae. Saudi Pharmaceutical Journal, 18: 1-25.

Griffin, G. (1956). An investigation of Anabaena unispora Gardner and other cyanobacteria as a possible mosquito factor in Salt Lake County, Utah. M.Sc. thesis, Dept Zoology, Univ Utah.

Hamlyn-Harris (1928). The relations of certain algae to breeding places of mosquitoes in Queensland. Bull. Entomol. Res., 18: 377-389.

Hartzell, A., P. Burchfieldh and V. F. Cotty (1958). Improvements in culturing larvae of Aedes aegypti (L.) for use in insecticide bioassay. Contrib. Boyce Thompson Inst. Rg., 320-326.

Hay, M. E. and W. Fenical (1988). Marine plant-herbivore interactions: the ecology of chemical defense. Ann. Rev. Syst. Ecol., 19: 111-145.

Hay, M E., W. Fenical and K. Gustafason (1987a). Chemical defense against diverse coral-reef herbivores. Ecology, 68: 1581-159.

Hay, M. E., J. E. Duffy, C. A. Pfister and W. Fenical (1987b). Chemical defense against different marine herbivores: are amphipods insect equivalents? Ecology 68: 1567-1580.

Hegazi, M. M., A. Pérez-Ruzafa, L. Almela, Ma E. Candela (1998). Separation and identification of chlorophylls and carotenoids from Caulerpa prolifera, Jania rubens and Padina pavonica by reversedphase high-performance liquid chromatography. Journal of Chromatography A, 829: 153-159.

Kamenarska, Z., M. J. Gasic and M. Zlatovic (2002). Chemical composition of the brown alga Padina pavonia (L.) Gaill. from the Adriatic Sea. Bot. Mar., 45: 339-345.

Kamenarska, Z., T. Taniguchi, N. Ohsawa, M. Hiraoka, and N. Itoh, (2007). A vanadium-dependent bromoperoxidase in the marine red alga Kappaphycus alvarezii (Doty) Doty displays clear substrate specificity. Phytochemistry, 68: $1358-66$.

Kiviranta, J. \& A. Abdel-Hameed (1994). Toxicity of the blue-green alga Oscillatoria agardhii to the mosquito Aedes aegypti and the shrimp Artemia salina. World Journal of Microbiology \& Biotechnology, 10: 517-520. 
Kiviranta, J., A. Abdel-Hameed, K. Sivonen, S. I. Niemeli and G. Carlberg (1993). Toxicity of cyanobacteria to mosquito Larvae-screening of active compounds. Environmental Toxicology and Water Quality, 8: 63-71.

Marten, G. G. (1984). Impact of the copepod Mesocyclops leuckarti pilosa and the green alga Kirchneriella irregularis upon larval Aedes albopictus (Diptera: Culicidae). Bulletin of the Society of Vector Ecologists, 9: 1.

Marten, G. G. (1987). The potential of mosquito-indigestible phytoplankton for mosquito control. J Amer Mosq Control Assoc., 3: 105-106.

Marten, G. G. (2007). Larvicidal Algae. Journal of the American Mosquito Control Association, 23(sp2): 177-183.

Merritt, R. W., R. H. Dadd, and E. D. Walker (1992). Feeding behavior, natural food, and nutritional relationships of larval mosquitoes. Ann Rev Entomol., 37: 349-376.

Pucazhendi, N., S. Pucazhendi, M. Vaitheeswaran, R. Shanmucasundaram and C. Lakshmanan (1995). Biologically active saltern and marine algal extracts for control of Culex quinquefasciatus larvae. Pesology, 19 (3): 291-301.

Rao, D. R., T. R. Mani, R. Rajendran, A. S. Joseph and A. Gajanana (1995). Development of a high level resistance to Bacillus sphaeticus in a field population of Culex quinquefasciatus from Kochi, India. Journal of the American Mosquito Control Association, 11: I-5.

Rao, D. R., C. Thangavel, L. Kabilan, S. Suguna, T. R. Mani and S. Shanmugasundaram (1999). Larvicidal properties of the cyanobacterium Westiellopsis sp. (blue green algae) against mosquito vectors. Trans. R. Soc. Trop. Med. Hyg., 93: 232.

Saxena, S.C. and L. Sumithra (1985). Laboratory evaluation of leaf extract of new plant to suppress the population of malaria vector Anopheles stephensi Liston (Diptera: Culicidae). Curr. Sci., 54: 201-202.

Schnitzler, I.; G. Pohnert, M. Hay and W. Boland (2001). Chemical Defense of Brown Algae (Dictyopteris spp.) against the Herbivorous Amphipod Ampithoe longimana. Oecologia, 126 (4): 515-521.

Semakov, V. V. and L. A. Sirenko (1985). Toxicity of some blue green algae on some insect larvae. Hydrobiol. J., 20: 72-75.

Steinberg, P.D., K. Edyvane, R. de Nys, R. Birdsey, I.A. van Altena (1991). Lack of avoidance of phenolic-rich brown algae by tropical herbivorous fishes. Mar. Biol., 109: 335-343.

Strickman, D. (1985). Aquatic Bioassay of 11 Pesticides Using Larvae of the Mosquito, Wyeomyia smithii (Diptera: Culicidae). Bull. Environ. Contam. Toxicol., 35: 133- 142.

Zubia, M., C. Payri and E. Deslandes (2008). Alginate, mannitol, phenolic compounds and biological activities of two range-extending brown algae, Sargassum mangarevense and Turbinaria ornata (Phaeophyta: Fucales), from Tahiti (French Polynesia). Journal of Applied Phycology, 20(6): 1033-1043. 

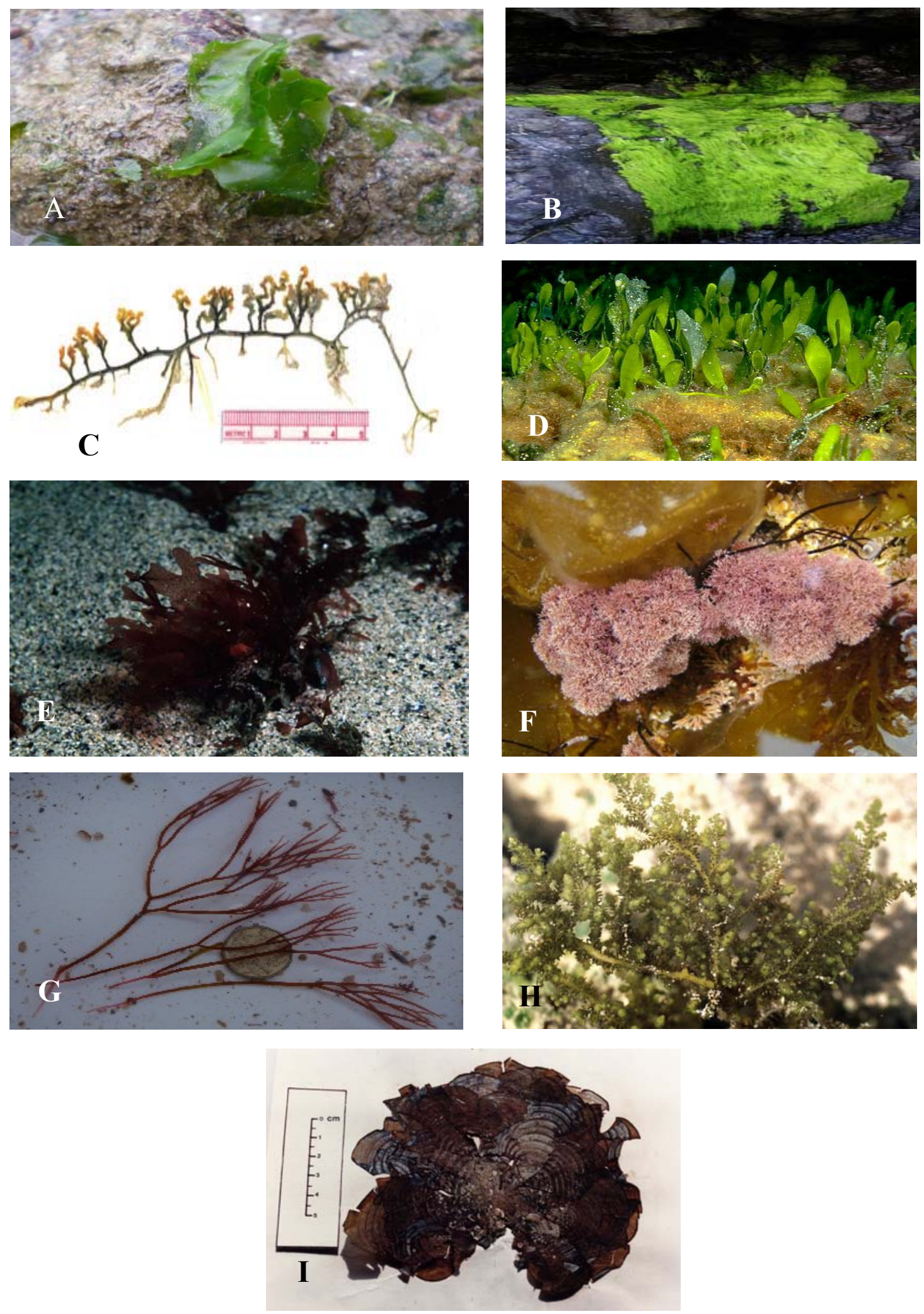

Plate 1. Seaweeds. Chlorophyta: (A) Ulva lactuca (B) Enteromopha intestinales (C) Caulerpa serrulata and (D) Caulerpa prolifera; Rhodophyta: (E) Nitophyllum punctatum (F) Jania rubens and (G) Sarconema filiforme; and Phaeophyta : (H) Cystoseira myrica and (I) Padina pavonica. 


\section{ARABIC SUMMARY}

أختبار بعض الطحالب البحرية من منطقة جنوب سيناء، البحر الاحمر كمبيدات بيولوجية على يرقات حشرة البعوض كيولكس بيييانس البين الاحتر

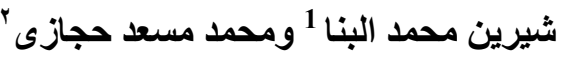

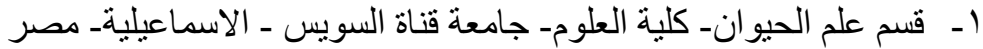

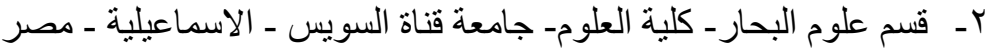

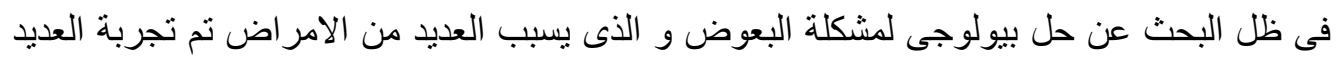

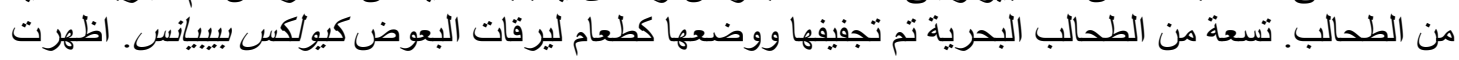

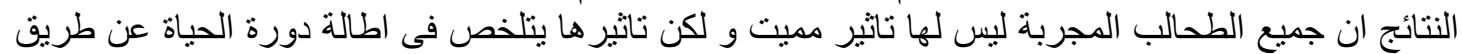

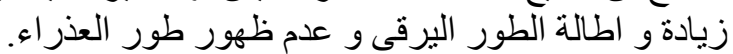

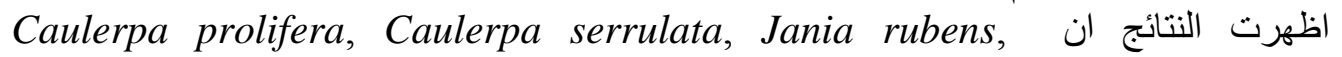
Nitophyllum punctatum, Cystoseira myrica and Padina pavonica من اكثر الانواع ثاثير ا مميتا و النى يمكن استخدامها كمبيدات حيوية بيولوجية للتخلص من حشرة البعوض

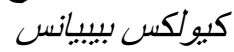

